\title{
ATITUDE BLASÉ E INTELIGÊNCIA: UMA BREVE DESCRIÇÃO DO HABITAT DO METROPOLITANO
}

\author{
Isabelle Sena Gomes, Universidade Federal da Paraíba - UFPB, Paraíba-Brasil \\ Iraquitan de Oliveira Caminha, Universidade Federal da Paraíba - UFPB, Paraíba- \\ Brasil
}

\section{RESUMO}

Este ensaio pretende discutir aspectos da "urbanidade" e pontos referentes ao intelecto do homem. O citadino acaba por desenvolver mecanismos de organização mental que irão ajuda-lo a lidar com os estímulos externos. A estes mecanismos, Simmel dá o nome de atitude blasé. O blasé é parte daquilo que podemos chamar de "objetividade da vida urbana", e colabora para a ocorrência das funções fáticas. Diversos autores versaram sobre blasé, objetividade, declínio dos laços afetivos e consanguíneos, de modo que mesmo tocando diferentes pontos, de alguma maneira os pensamentos de: Gadamer, Simmel e Magnani encontram-se (consonante ou dissonantemente), relacionados.

Palavras-Chave: Blasé; Inteligência; Impessoalidade; Cidade.

\section{ACTITUD BLASÉ E INTELIGENCIA: EL HOMBRE Y HÁBITOS URBANITAS}

\section{RESUMEN}

Este trabajo tiene como objetivo discutir los aspectos de la "urbanidad" y puntos para el intelecto de la ciudad. La ciudad finalmente desarrollar mecanismos de organización mental que le ayudarán a hacer frente a los estímulos externos. En estos mecanismos, Simmel da el nombre de la actitud displicente. El indiferente es parte de lo que llamamos "la objetividad de la vida urbana", y contribuye a la aparición de las funciones de los hechos. Varios autores estaban a punto indiferente, la objetividad, la disminución de los vínculos emocionales y familiares, por lo que incluso tocando diferentes puntos, de alguna manera el pensamiento: Gadamer, Simmel y Magnani son (consonante o dissonantemente) relacionados.

Palabras-Clave: Blasé; Inteligencia; La impersonalidad; Ciudad.

\section{BLASÉ ATTITUDE AND INTELLIGENCE: A BRIEF DESCRIPTION OF THE METROPOLITAN HABITAT}

\begin{abstract}
This essay aims to discuss aspects of "urbanity" and some points regarding the city's intellect. Considering that the city is made by / for the very people who inhabit it, and its (re) construction is synonymous with reconstruction of the subject, this text will deal with the dialectical relationship between individual and city-intelligence. Such processes occur because of trade and liminaridades everyday, and the interaction of man Conexões: revista da Faculdade de Educação Física da UNICAMP, Campinas, v. 11, n. 4, p. 147-158, out./dez. 2013. ISSN: 1983-9030
\end{abstract}


with all that comprise the city. Before thinking about how man interacts with the city, we raise the question of intelligence as part of the dialogue-person town. Sometimes, the city eventually develop certain mechanisms of mental organization, which will help you cope with the wave of stimuli coming from outside. In these mechanisms, Simmel gives the name of blasé attitude. The blasé is part of what we call "objectivity of urban life," and contributes to the occurrence of the functions of phatic communication. Phatic functions, in turn, are defined as an attempt to maintain communication for the purposes of socializing, but in a way impersonal. Several authors were about the blasé about the objectivity of urban life, about the decline of the bonding and kin, so that even touching difetentes points somehow - viewed from a panoptic - the thought: Park, Gadamer, Simmel, Certau, Mayol, Magnani and Wirth, are (consiliently or dissonantly) related.

Key-Words: Blasé; Intelligence; Impersonality; City. 


\section{INTRODUÇÃO}

No final do século XIX, a Antropologia encontrava-se imersa em questões ligadas aos povos ditos "primitivos" devido à curiosidade coletiva sobre seu contraste com as sociedades ditas "civilizadas". Tradições, costumes e rituais próprios dos povos exotizados despertaram por muito tempo o interesse nos costumes dos "nativos", visando inclusive, descobrir se estes pertenciam ao gênero humano. ${ }^{1}$

Em seu texto, Viveiros de Castro $^{2}$ - influenciado pelo estruturalismo de Levi-Strauss ${ }^{3}-$ conta que nas Grandes Antilhas, enquanto os Europeus investigavam se os indígenas tinham alma, os nativos queriam saber se os corpos brancos eram dotados das mesmas características que os corpos deles. Isto denuncia a existência de um pensamento dicotômico, que separa natureza e cultura em duas dimensões diferentes, porém interconectadas; ao mesmo tempo em que quebra qualquer percepção pré-concebida de quem são de fato "os outros", e até onde estão os limites entre nós e eles. Reconhecer-se em algum momento como "o outro", em relação aos sujeitos sociais, ajuda a reconstruir a percepção das coisas e quebrar certezas reificadas.

Com a ampliação das pesquisas e discussões Antropológicas, e também a proposição de que em algum momento os povos indígenas poderiam ser "extintos" (resultando no esgotamento do principal "objeto de estudo"), essas e outras questões mais elementares acerca do contraste "selvagem"/“civilizado", serviram como base para o desenvolvimento de novas pesquisas em campos para além das fronteiras das sociedades primitivas. Isto resultou em um movimento de crescimento e ampliação dos "horizontes antropológicos", e a Antropologia deslocou seu foco do ideal evolucionista, expandindo o olhar na direção do "ver o diferente como diferente e não como sinônimo de atrasado". Com isto, outros campos de investigação importantes, não necessariamente vivenciados além-mar, despertaram o interesse dos Antropólogos, como por exemplo: a cidade. ${ }^{1}$ Com isto, não se ignora a importância da pesquisa em culturas tradicionais, pois, se

A Antropologia segue estudando [...] não é por uma estranha fidelidade a antigos modelos ou puro conservadorismo, mas porque as questões levantadas pelo modo de vida [...], escala e temporalidade dessas sociedades continuam enriquecendo os métodos de pesquisa e alimentando a reflexão. ${ }^{1}$

Conexões: revista da Faculdade de Educação Física da UNICAMP, Campinas, v. 11, n. 4, p. 147-158, out./dez. 2013. ISSN: 1983-9030 
Para Park, ${ }^{4}$ esse campo de investigação é caracterizado por algo que vai além dos aspectos urbanísticos e/ou geográficos e ambientais. A cidade é assim denominada por possuir um universo próprio de organização vital dos citadinos que a compõem, configurando-se como produto da natureza também, mas principalmente da natureza humana. Talvez este olhar abra espaço para estudos que de alguma forma polarizam opostamente cidade e campo para fins de comparação, mas isto foge ao escopo deste ensaio. Lançando um olhar mais mercadológico sobre este campo de investigação, pode-se dizer que nos textos de Park, ele inclina-se na direção do pressuposto Weberiano de que a cidade seria um espaço de troca e mercado.

Anos mais tarde, David Harvey (baseado nos estudos de Park) escreveu sobre o processo de "construção" mútua citadino-cidade que "a mesma casa que edificamos é a casa que nos edifica ${ }^{i,}, 5$ Em outros termos, o autor quis dizer que a cidade que o homem (re)monta é a cidade na qual ele terá que viver, pois à medida que o homem planeja, constrói e lida com a cidade, ele está lidando consigo mesmo ${ }^{\text {ii }}$. Com esta proposição, Harvey não torna o homem o normalizador dos processos que ocorrem na cidade; tão pouco ignora a sua inserção em um sistema institucionalizado. Em contrapartida, ele lembra a importância de não nos deixarmos reduzir ao papel de "impotentes marionetes". Vindo ao encontro deste pensamento, Michel Agier ${ }^{6}$ escreve que a cidade é feita pelas próprias pessoas que a habitam. Na percepção de Certau, ${ }^{7}$ os corpos caminhantes que movimentam (-se n) a cidade ajudam a escrever um texto urbano mas nem sempre podem lê-lo. Gilberto Velho ${ }^{8}$ corrobora com a proposta de Harvey quando fala na metamorfose. A metamorfose ${ }^{\mathrm{iii}}$ para ele possibilita "através do acionamento de códigos associados aos contextos e domínios específicos - portanto, universos simbólicos diferenciados - que os indivíduos estejam sendo permanentemente reconstruídos".

A vida urbana, após o período da revolução industrial, dirigiu-se para a prevalência do trabalho fabril, da intelectualidade, do desejo de estabelecer controle e ordem em uma

\footnotetext{
i Fazendo referência a um antigo ditado grego.

ii Para Marcelo CASTAÑEDA (2010, p. 255), "tanto a ordem social quanto a individualidade podem ser vistas como resultantes das práticas".

iii Viveiros de Castro emprega outra noção de metamorfose em seu texto, que vai além da simples mudança subjetiva e atinge o domínio daquilo que transcende: "A metamorfose reintroduz o excesso e a imprevisibilidade na ordem humana: transforma os homens em animais ou espíritos [...]"

Conexões: revista da Faculdade de Educação Física da UNICAMP, Campinas, v. 11, n. 4, p. 147-158, out./dez. 2013. ISSN: 1983-9030
} 
atmosfera relativamente estável. Os atores da cidade tornaram-se cada vez mais “objetivos", aderindo à forma de pensar baseada em um modo calculista de vida, marcada pela pontualidade, exatidão, tradução de sentimentos e sensações em números. Uma vida segura e controlada, na qual tudo é previamente pensado. ${ }^{9}$ Em contraste com esta forma de vida, pouco a pouco se instalou o ideal da "pós-modernidade" ligado a um conceito (teoricamente) distinto de trabalho, alimentado pela liberdade.

A liberdade segundo Bauman, ${ }^{10}$ é característica indispensável para o homem "pósmoderno". Ela é ao mesmo tempo libertadora e carcereira, fomentadora de angústias. Neste contexto, o trabalho, a vida, o lazer, os desejos/escolhas e as relações interpessoais; passaram a ser marcados por um "pseudolivre arbítrio". O livre arbítrio permite, entre outras coisas, que cada indivíduo busque a sua própria evolução no âmbito da subjetividade (no tocante ao universo psicológico), e da objetividade (no que diz respeito ao ganho de conhecimento, por exemplo). Busca-se com isto alcançar seu espaço no cenário urbano e no mercado de trabalho, cada vez mais especializado. $\mathrm{O}$ "novo" trabalho especializado trouxe consigo a valorização do conhecimento, em detrimento do sistema de produção em massa predominante nas grandes fábricas, nos séculos XIX e XX. Assim, os citadinos voltaram-se para a sua individualidade na proporção em que se distanciaram nas relações interpessoais.

Segundo Simmel, ${ }^{9}$ o comportamento mental do homem urbano é caracterizado pela especialização, distanciamento das relações afetivas e pela intelectualização - que seria uma espécie de "afastamento aproximado" do indivíduo em relação aos estímulos provindos da cidade. ${ }^{11}$ Este afastamento, a longo prazo, gera uma série de mecanismos internos - como contatos superficiais e indiferença - capazes de proteger o pensamento e/ou a inteligência de um número grande de estímulos. Em outras palavras, os habitantes da cidade passam com o tempo a agir menos com os sentimentos e mais com a razão. A este conjunto de mecanismos internos $\operatorname{Simmel}^{7}$ deu o nome de atitude blasé. Apesar de ser um tema levantado por Simmel em meados de 1902, a temática do blasé é totalmente pertinente e contemporânea.

Esta proposição pode nos ajudar a compreender porque é tão recorrente o uso da "função fática", conforme citou. ${ }^{9}$ A função fática trata-se de um esforço para assegurar 
a comunicação com um individuo com o qual se deseje contato, porém de forma superficial. Relacionado à caminhada na cidade, o fático faz com que ela presiga e se faça perseguir, "criando uma organicidade móvel do ambiente", em outras palavras, um encontro de topoi fáticos em um labirinto de ecos.

A cidade tal qual a concebemos, é o lugar em que o sujeito se encontra imerso em um universo de informações constantemente movimentado. Um grande macrocosmo rico de microcosmos, que podem ser olhados de formas diferentes e de acordo com o objeto de estudo de cada pesquisador. Os bairros, amplamente estudados por diversos autores em suas particularidades, as "tribos urbanas", os espaços, pedaços e manchas ${ }^{1}$ são formas distintas de olhar e interpretar.

Essa gama de possibilidades demonstra a riqueza e diversidade cultural metropolitana contida dentro de um espaço, que visto panopticamente - como ocorre se observarmos a cidade do alto de um arranha céu ${ }^{\text {iv }}$ - parece ser um todo homogêneo, onde a gigantesca massa que se imobiliza sob o olhar. ${ }^{6: 12}$ Contudo, como bem observou Certau, ${ }^{7}$ se olharmos mais de perto cada transeunte veremos que os passos, e percursos são atos qualitativos singulares, que marcam a interação do sujeito com a cidade. Um exemplo disto é a forma como as pessoas lidam com "obstáculos" físicos típicos da cidade (objetos, orelhões, postes, pessoas, etc.), bem como com os diversos anúncios, letreiros e informações disponíveis, que suscitam o olhar do sujeito em seu trajeto.

Isto nos remete ao pensamento de Simmel, ${ }^{7}$ que escreve que o citadino está diariamente diante de uma gama imensurável de imagens e estímulos provindos dos meios de comunicação, dos outros e da própria cidade. Segundo o autor, para conseguir manter um estado de equilíbrio "sóciobiológico", o sujeito precisa criar mecanismos psicológicos de defesa em relação à cidade, tornando-se cada vez mais "objetivo". O termo "sociobiológico" é usado por Velho ${ }^{8}$ para descrever a natureza do mecanismo, que segundo a tese de Simmel, ${ }^{7}$ influencia no equilíbrio mental em decorrência da exposição às informações da metrópole.

\footnotetext{
${ }^{\text {iv }}$ Metáfora usada por CERTAU (1996) para conduzir os leitores à experiência de distanciar-se da massa, transfigurando o observador em voyeur.

Conexões: revista da Faculdade de Educação Física da UNICAMP, Campinas, v. 11, n. 4, p. 147-158, out./dez. 2013. ISSN: 1983-9030
} 
De acordo com Simmel, ${ }^{7}$ a metrópole é o lugar onde ocorrem os processos objetivos e subjetivos do homem urbano, sendo o conflito entre a cultura - de fora para dentro - e as respostas internas - de dentro pra fora, o maior problema da "vida moderna". A objetividade da vida moderna exige do sujeito uma forma de pensar baseada em um modo calculista de vida, marcado pela pontualidade, exatidão, tradução de sentimentos e sensações em números, de modo que todas as atitudes - principalmente no que diz respeito às relações interpessoais - acabam sendo previamente pensadas.

Mas antes mesmo de identificarmos em que direção o homem da cidade aponta seus desejos, interações sociais, esquemas cognitivos e afetivos; colocamo-nos diante de outra questão que parece anterior a tudo isto: o problema da inteligência. Partindo do pressuposto que é na inteligência que muitos destes esquemas são processados, colocamos como questão central entender o que é de fato a inteligência, e como ela dialoga com os estímulos na cidade.

É sabido que para que haja inteligência, um conjunto de estruturas (físicas e/ou psíquicas) articula-se no universo do corpo e da mente, produzindo constantemente, em um sistema retroalimentado, novas formas de perceber(-se) (n)o mundo. É sobre esta dinâmica incessante, fruto da estável instabilidade humana, que buscaremos refletir neste ensaio.

Tomando como referência as ideias de Gadamer, ${ }^{13}$ é válido considerar que a inteligência é a mediadora entre aquilo que o homem pensa, e o que ele pensará, levando em conta que existem fatores de caráter social e biológico incidindo diretamente nestas (re)construções. Isto nos conduz a concebê-la como produtora - e em certa medida produto - do pensamento, e, portanto, do conhecimento. Em outros termos, a inteligência proporciona não só a curto, mas também a longo prazo, o ser-capaz-defazer $^{13}$ simbólico, próprio do comportamento humano. Assim, a capacidade de reflexão, autocrítica e crítica cultural, são de responsabilidade da inteligência; e a perda destas, resultaria em um estado de desequilíbrio marcado pela falta, e consequentemente na perda da liberdade, que podemos chamar de doença.

Conexões: revista da Faculdade de Educação Física da UNICAMP, Campinas, v. 11, n. 4, p. 147-158, out./dez. 2013. ISSN: 1983-9030 
Do pensamento de Gadamer ${ }^{13}$ retiramos a premissa de que o ser-capaz-de-fazer aliado à reflexibilidade e ao distanciamento autoconsciente, caracterizam a possibilidade de manter-se livre de doença, e portanto saudável. No entanto, não podemos deixar de considerar que o problema da inteligência transcende o que é da ordem da relação mente/corpo e invade o campo das relações sociais inerentes ao habitat do citadino sob a forma de uma gama de estímulos externos.

Estrar em sintonia com o mundo e consigo é condição sine qua non para manter-se saudável, de modo que a doença mental pode ser caracterizada pela perda desta capacidade. Entendendo que o homem moderno tem como habitat a cidade, é impossível não levar em conta o desafio de permanecer equilibrado, diante do bombardeamento de informações, ideias, conceitos e formas de sedução. Estudos desenvolvidos neste "campo" apontam para o leque de convites aos sentidos, que são tão diversificados quanto o cosmopolitismo que caracteriza as metrópoles. Isto nos leva a crer que os trajetos por entre os cenários urbanos tornam-se uma experiência não só de deslocamento, mas de interação. Nesse processo, o sujeito acaba por desenvolver, ao longo dos anos, estratégias de convivência, pois, a todo o momento é colocada à prova sua capacidade de estabelecer diálogo entre o micro e o que é macro, o individual e o coletivo, o habitante e o habitat. Se para manter-se saudável é necessário o equilíbrio entre estes aspectos - aqui polarizados para fins de exemplificação - atitudes como o blasé podem ser pensadas no contexto da cidade como um recurso do qual indivíduo moderno lança mão, na tentativa de preservar-se em certo ponto distanciado dos estímulos provindos da cidade.

Imersas em uma gama de estímulos provindos do meio urbano - que limitam ou não as relações, conforme Simmel e Velho escreveram - as dimensões objetiva e subjetiva da vida do citadino alternam-se. Nesse balanço, a impessoalidade da vida moderna emerge hora como atitude blasé, hora como mecanismo de defesa/desconfiançav ${ }^{\mathrm{v}}$.

Assim como atitude blasé, distanciamento e intelectualização, a vida urbana provoca nos sujeitos a superficialidade das relações, e com isso o enfraquecimento dos laços

\footnotetext{
${ }^{v}$ Apesar de ser característica abordada principalmente nos estudos acerca da cidade, o blasé não é exclusividade da urbe.

Conexões: revista da Faculdade de Educação Física da UNICAMP, Campinas, v. 11, n. 4, p. 147-158, out./dez. 2013. ISSN: 1983-9030
} 
vicinais, de sangue e de parentesco em detrimento das circulações/interações sociais "associadas a experiências, combinações e identidades particulares, individualizadas". 8 Este conjunto de características gera uma atmosfera de substituição dos vínculos por algo impessoal, prático e universal, ou por um mecanismo nivelador como o dinheiro, de modo que laços secundários são construídos com base no trabalho, na convivência, etc, ${ }^{10}$ - uma espécie de "solidariedade mecânica".

Ainda sobre a atitude blasé, Harvey ${ }^{5}$ faz referência à Simmel ${ }^{7: 221}$ definindo o blasé como "a fonte de toda indiferença" e cita como exemplo do que ele chama de "Nirvana estupidificado" os shopping malls e as utopias degeneradas. Harvey ${ }^{5}$ ainda escreve que - naquele contexto, a cidade de Baltimore - os locais produtores de atitudes blasé tem como objetivo gerar uma indiferença política. Gilberto Velho ${ }^{8}$ versou sobre o blasé em uma ótica diferente - não oposta, mas em certo ponto complementar ao pensamento - de Simmel. Em seu texto, ele olhou o blasé como um mecanismo de defesa próprio de alguns citadinos. No entanto, ao citar e descrever o caso do "preto velho" em Copacabana, Velho ${ }^{8}$ percebeu que a atitude blasé era em certo ponto relativa. Isto porque, diante das mesmas situações, pessoas reagiam de formas diferentes. Esta proposição está expressa no seguinte fragmento:

De algum modo, parte dos comportamentos descritos pode estar relacionada à atitude blasé, descrita por Simmel, com os indivíduos se protegendo de um 'excesso de estímulos'. Mas o que julgo mais significativo é a explicitação de um campo de possibilidades próprio à sociedade complexa moderna. ${ }^{8}$

É importante ressaltar que Velho, ${ }^{8}$ ao discutir o ideal de blasé à luz da teoria de Simmel, ${ }^{9}$ reconhece que o mesmo construiu sua tese no início do século XX, no entanto, destaca a sua importância - assim como de Schutz- para o entendimento da coexistência de diferentes mundos na sociedade complexa bem como dos contatos sociais na cidade.

Muitas dos contatos estabelecidos na cidade são pautados por aquilo que Mayol ${ }^{14}$ chamou de "Conveniência". Segundo Mayol, conveniência seria grosso modo o compromisso que cada pessoa assume, abrindo mão das pulsões individuais. Assim, os estereótipos da conveniência são uma manipulação da distância social e se exprimem sob a forma negativa de um "até onde se vai para não ir longe demais". Neste cenário, 
emergem as expressões que Certau ${ }^{7}$ e Mayol $^{14}$ chamaram de "fáticas". Tais expressões teriam como objetivo o contato superficial, impessoal, remetendo-nos ao "afastamento aproximado". Entre estas expressões, observamos o uso do "oi", "faz calor", "mande lembranças para a família", entre outras. Além disso, o hábito crescente de mandar beijos e abraços, no lugar de dá-los.

Sobre a conveniência e as relações sociais no cenário urbano, Mayol ainda escreve que apesar do contato de base fática objetivar a manutenção - ainda que de modo superficial - destas relações, o corpo pode denunciar um discurso que nem sempre é falado. Este discurso às vezes, com certa perspicácia por parte do observador, pode ser "lido", pois ultrapassa o domínio do pensamento transformando-se em linguagem gestual, linguagem corporal. Há que se conferir ênfase no que é expresso pelo olhar e pelas mãos. Em outros termos, para manter-se conveniente, é necessário mediar sinais e respostas corporais e pensar sobre como agir, exigindo racionalidade associada ao arcabouço gestual. De certo modo, esta proposição nos remete mais uma vez ao pensamento de Simmel, ${ }^{9}$ que fala de uma possível "proximidade corporal" e "distância espiritual", possivelmente relacionadas ao sentimento de estar entre uma infinidade de pessoas na metrópole e ao mesmo tempo ser sujeito "só".

O cosmopolitismo facilita a integração e atração de pessoas, à medida que transforma a cidade em um lugar para "todos", pois, quanto mais heterogênea a cidade, mais aberta à novas tendências, grupos sociais e discursos coletivos. No entanto, apesar de ser heterogênea, dentro da cidade existem espaços de segregação, e esta segregação envolve fatores como: faixa etária, etnia, raça, preferências, e por causa dela, "cidades" dentro de "cidades" são erguidas. ${ }^{4}$

O grande paradoxo desta questão é que os discursos coletivos são elaborados com base em vários discursos individuais, no entanto, o sujeito parece não reconhecer nestes a sua individualidade. Nesse sentido, o homem vive uma ambiguidade, e a cidade é o cenário privilegiado desse estilo de vida complexo e rico de particularidades. ${ }^{10}$ 


\section{REFERÊNCIAS}

${ }^{1}$ MAGNANI, J. G. C. A antropologia urbana e os desafios da metrópole. São Paulo, v.

15, n. 1 , abr. 2003. Disponível em:

$<$ http://www.scielo.br/scielo.php?script=sci_arttext\&pid=S0103-

20702003000100005\&lng=en\&nrm=iso>. Acesso em: 02 jan. 2013.

${ }^{2}$ VIVEIROS DE CASTRO, E. V. Os pronomes cosmológicos e o perspectivismo ameríndio. Mana, Rio de Janeiro, v. 2, n. 2, p. 115-144, 1996.

${ }^{3}$ LEVI-STRAUSS, C. Race et histoire. In: Anthropologie structurale deux. Paris: Lon. 1973 [1952]. p. 377-422.

${ }^{4}$ PARK, R. E. A cidade: sugestões para a investigação do comportamento humano no meio urbano. In: Velho, O. G. (Org.). Fenômeno urbano. Rio de Janeiro: Zahar, 1976.

${ }^{5}$ HARVEY, D. Os espaços de utopia. In: Espaços de esperança. São Paulo: Loyola, 2004.

${ }^{6}$ AGIER, M. Antropologia da cidade. São Paulo: Terceiro Nome, 2011.

${ }^{7}$ CERTEAU, M. de. A invenção do cotidiano: artes de fazer. Petrópolis: Vozes, 1996.

${ }^{8}$ VELHO, O. G. Unidade e fragmentação em sociedades complexas. In: Velho, O. G. Projeto metamorfose: antropologia das sociedades complexas. Rio de Janeiro: Zahar, 1994.

${ }^{9}$ SIMMEL, G. A Metrópole e a Vida Mental. In: O fenómeno urbano. VELHO, O. G. (Org.). 4. ed. Rio de Janeiro: Zahar, 1979.

${ }^{10}$ BAUMAN, Z. O mal-estar da pós-modernidade. Rio de Janeiro: Zahar, 1998. 
${ }^{11}$ WIRTH, L. O urbanismo como modo de vida. In: VELHO, O. G. (Org.). Fenômeno urbano. Rio de Janeiro: Zahar, 1973

${ }^{12}$ WHYTE, W. F. Sociedade de esquina: a estrutura social de uma área pobre e degradada. Rio de Janeiro: Zahar, 2005.

${ }^{13}$ GADAMER. H. G. O caráter oculto da saúde. Petrópolis: Vozes, 2006.

${ }^{14}$ MAYOL, P. O bairro. In: CERTEAU, M. A invenção do cotidiano. Rio de Janeiro: Vozes, 1996

Recebido em: 01 ago. 2013

Aceito em: 03 set. 2013

Contato: Iraquitan de Oliveira Caminha

iraqui@uol.com.br 